\title{
AIDS and the Psychogeriatrician
}

Cornelius L. E. Katona, Senior Lecturer in Psychiatry with Special Interest in the Elderly, University College and Middlesex School of Medicine, London

It might at first sight appear that old age psychiatrists and geriatricians are relatively well protected from having to deal with the problems of patients suffering from the Acquired Immune Deficiency Syndrome (AIDS). It is therefore perhaps surprising that the major article in the newsletter of the American Geriatric Society is devoted to AIDS and concludes that "there is no question that the AIDS epidemic is the most important world wide public health issue of this century". 1

AIDS was originally conceptualised in clinical terms as the development of a reliably diagnosed disease indicative of underlying cellular immune deficiency in a person with no known underlying cause of such immune deficiency. ${ }^{2.3}$ Since the first cases were reported in 1981, understanding of the pathological processes underlying the disease has developed apace. It is now clear that the syndrome appears to be caused by retrovirus infection, a great majority of cases being associated with a particular virus known as the Human Immunodeficiency Virus (HIV). Infection with HIV appears to follow a characteristic sequence of stages from acute seroconversion, through a period of asymptomatic infection (which may last several years) to a variety of later and more serious manifestations of immune deficiency, culminating in the full-blown clinical picture of AIDS which may be dominated by opportunistic infection (protozoal, fungal, bacterial or viral) and/or by a variety of characteristic malignancies, particularly Kaposi's Sarcoma and lymphoid tumours.

The predominant 'high risk' groups have been well publicised in the media. The overwhelming majority of cases in the United States and in the United Kingdom are in homosexual men and intravenous drug users. The administration of infected blood products either through transfusions or in the treatment of haemophilia are also well recognised as risk factors. In Africa, where it is thought that the infection originated, transmission is almost entirely by heterosexual contact and there is an increasing number of such cases reported, involving both male to female and female to male spread, in the West. ${ }^{2}$ Although at present the disease appears relatively uncommon outside the age range of $15-50$, cases in elderly people continue to be reported. Transfusions of blood products are currently the most important route of infection in patients over 60 years of age ${ }^{4}$, although cases related both to homosexual contact and to intra-

This is a revised version of a talk given to the Section for Old Age of the Royal College of Psychiatrists on 17 December 1987. venous drug abuse may occur in this age group. In the United States $10 \%$ of AIDS cases are estimated to be in individuals over 50 years of age; by 1990 there may be 27,000 cases of AIDS in persons over the age of 50 and 1100 in those over $70 .^{1}$

The AIDS epidemic is clearly growing. By the end of September 1987, 7557 patients had been reported as HIV positive in the United Kingdom and 1067 of them had AIDS. Of the latter, 605 had already died. ${ }^{5}$ Asymptomatic HIV infection is not only much commoner than AIDS but it is likely that most HIV positive subjects are undetected. The size of the asymptomatically infected population and the risk, once infected, of developing AIDS remain subjects for debate. Rees ${ }^{6}$ considers that the most economical statistical model is of infection invariably leading to AIDS unless death from another cause supervenes. According to this model, progression from infection to AIDS takes a mean of 15 years with a standard deviation of five years. An alternative model $^{7}$ postulates that there are two populations of HIV infected subjects: those who go on to develop AIDS and those without long term sequelae. In this model there is a shorter mean interval of about eight years between infection and AIDS. The conclusions of these models vary in terms of their estimates of new infection rate, pattern of infectivity, and prognosis but there is general agreement that the current number of HIV positive subjects exceeds that of AIDS patients by a factor of about 25 and that a minimum of $35 \%$ of them will subsequently develop AIDS. ${ }^{2}$ The prognosis in AIDS appears to depend on the initial clinical presentation. Subjects with Kaposi's sarcoma have a life expectancy of nearly two years whereas the mean expectancy in those where the initial clinical presentation is with Pneumocystis Carinii pneumonia is about one year. $^{2}$

HIV infection and AIDS have been associated with a number of psychiatric complications. Anxiety related syndromes in the 'worried well' from high risk groups have frequently been reported ${ }^{3.8}$ as well as delusions of AIDS infection in psychiatric patients. ${ }^{9}$ Patients learning that they have AIDS infection frequently go through a characteristic sequence of stages of grieving analogous to those in bereavement; ${ }^{10}$ these include shock, denial, guilt, persistent depressive symptomatology, acceptance and resignation. Major depression occurs in $5 \%$ of patients with asymptomatic HIV infection and about $14 \%$ of those with AIDS related complex and AIDS. ${ }^{11}$

Neuropsychiatric complications, which have been termed collectively the 'AIDS dementia complex', have 
also been reported in patients with HIV infection. These may be due in some cases to opportunistic CNS infections, particularly with cytomegalovirus and Ebstein-Barr virus, but the most frequent cause is probably direct CNS infection with HIV, which has been isolated with brain tissue at post mortem. Early reports were of a sub-acute encephalitis presenting initially with malaise, social withdrawal, lethargy and loss of libido with the subsequent manifestations of a progressive dementia characterised by psychomotor retardation, incontinence and confusion. Evidence is emerging ${ }^{11}$ that cognitive deficits are extremely commonly associated with HIV infection. Up to $44 \%$ of otherwise asymptomatic HIV positive subjects, $54 \%$ of those with AIDS related complex and as many as $87 \%$ of those with AIDS, show cognitive deficits on formal testing. These deficits have been reported mainly in terms of specific deficits on detailed neuropsychological testing (reduced verbal fluency, verbal memory and problem solving ability). ${ }^{10}$ It is not as yet clear how disabling AIDS dementia complex is in practical terms and still less clear how frequently and with what speed progression to the late stage of muteness, incontinence and paraplegia occurs. Since motor disabilities (weakness, tremor, ataxia, etc.) have also been reported $^{12}$ it is also not clear whether the late stages of the syndrome are primarily related to cognitive or to motor deficits.

There has so far been little uniformity in patterns of management for AIDS patients, and estimates of the cost of care have varied widely. Hardy et al ${ }^{13}$ pooled data from several United States centres to estimate the total cost of health care until death of the first 10,000 US AIDS patients as $\$ 140,000$ per head with an average hospital stay of 168 days. Total costs in terms of the consequences of disability and premature death were estimated as almost half a million dollars. United Kingdom costs, though lower, are still substantial. The first 33 cases treated at the Middlesex Hospital spent an average of 50 days in hospital and incurred $\mathbf{1 6 8 0 0}$ each in direct hospital costs with immediate overall cost implications of $£ 388,000$ revenue and $£ 472,000$ capital in the $1986 / 87$ financial year. ${ }^{14}$

If cognitive and motor deficitis occur relatively early in the disease process it is likely that they will be important influences on the need for long term care of HIV positive patients. It is widely assumed both in the United States ${ }^{1}$ and in the United Kingdom ${ }^{15}$ that most AIDS patients will be cared for in the community. Adler proposes that a system of hostels and terminal home care teams with provision of acute hospital beds for the treatment of acute exacerbations of infections or cancers will be necessary.

Community care for AIDS patients may not be cheap; Cunningham \& Griffiths ${ }^{16}$ estimated the cost of one year's community care including one month as an in-patient would be almost $f 22,000$. Ironically it is likely that the widespread introduction of treatment with zidovudine will not only be expensive in itself in pure drug costs and the increased need for transfusions, but that any resultant increased survival may be increased survival with disability and an increased burden of care costs.
Quite apart from cost, it is far from clear what expertise is needed to ensure appropriate delivery of care to the increasing population of AIDS victims. Some lessons may be learnt from the hospice movement although life expectancy in AIDS is much longer than that normally dealt with in hospices. The general adult psychiatric service has some experience of dealing with chronic illness in a young to middle-aged population and lessons may also be learnt from the care of the severely brain damaged.

Geriatricians and psychogeriatricians are all too well used to the problems of caring for a large and growing population with progressive cognitive and behavioural deficits, and at the very least may be called upon to care for the relatively small but growing number of elderly patients with AIDS. It would, however, be both practically and philosophically unacceptable to attempt to care for the much younger majority of AIDS patients in the hospital and community care settings currently available for the demented elderly.

Appropriate provision for AIDS dementia victims must be planned and funded before pragmatic solutions are forced upon us by the pressure of increasing numbers. Psychogeriatric expertise is likely to be of use in planning such services. It may even be that, as was concluded in a recent editorial from the American Geriatric Society, ${ }^{17}$ "the systems and resources developed principally for chronically ill elderly persons must now prepare to serve another younger and equally needed segment of society". It is possible that, as a professional group, we are the most suitable providers of care for patients with AIDS dementia. It is almost certain that we will be asked to provide such care. It is up to us not only to ensure that care for these patients is provided appropriately but that this is not done at the expense of our own equally needy and fast growing population of elderly demented patients.

\section{REFERENCES}

${ }^{1}$ Crossley, K. \& Henry, K. (1987) AIDS: Implications for longterm care. Clinical Report on Aging, 1, 2-9.

${ }^{2}$ ADLER, M. W. (1987) ABC of AIDS: Development of the epidemic. British Medical Journal, 294, 1083-1085.

${ }^{3}$ FENTON, T. W. (1987) AIDS-related psychiatric disorder. British Journal of Psychiatry, 151, 579-588.

${ }^{4}$ Moss, R. J. \& MiLes, S. H. (1987) AIDS and the geriatrician. Journal of the American Geriatric Society, 35, 460-464.

${ }^{5}$ British Medical Journal (1987) Latest UK figures on AIDS. British Medical Journal, 295, 1004.

${ }^{6}$ Rees, M. (1987) Issues in AIDS epidemiology. Paper prepared for the Royal Statistical Society AIDS meeting, 25 November 1987.

'Anderson, R. M., Medley, G. F., Blythe, S. P. \& Johnson, A. M. (1987) Is it possible to predict the minimum size of the acquired immune deficiency syndrome (AIDS) epidemic in the United Kingdom? Lancet, i, 1073-1075.

${ }^{8}$ FAULSTICH, M. E. (1987) Psychiatric aspects of AIDS. American Journal of Psychiairy, 144, 551-556.

${ }^{9}$ Riccio, M. \& Thompson, C. (1987) Pseudo-AIDS, AIDS panic or AIDS phobia. British Journal of Psychiatry, 151, 863.

${ }^{10}$ GolDMEIER, D. (1987) Psychosocial aspects of AIDS. British Journal of Hospital Medicine, 37, 232-240. 
${ }^{11}$ Burton, S. W. (1987) The psychiatry of HIV infection. British Medical Journal, 295, 228-229.

${ }^{12}$ Navia, B. A., Jordan, B. D. \& Price, R. W. (1986) The AIDS dementia complex: I. Clinical features. Annals of Neurology. $19,517-524$.

${ }^{13}$ Hardy, A. N., Rauch, K., Echenberg, D., Morgan, W. M. \& Curran, J. W. (1986) The economic impact of the first 10,000 cases of acquired immune deficiency syndrome in the United States. Journal of the American Medical Association, 255, 209211

14Johnson, A. M., Adler, M. W. \& Crown, J. M. (1986) The
Acquired Immune Deficiency Syndrome and epidemic of infection with human immuno-deficiency virus: costs of care and prevention in an inner London district. British Medical Journal, 293, 489-492.

${ }^{15}$ ADLER, M. W. (1987) Care for patients with HIV infection and AIDS. British Medical Journal, 295, 27-29.

${ }^{16}$ Cunningham, D. \& Griffiths, S. F. (1987) AIDS: Counting the cost. British Medical Journal, 295, 921-922.

${ }^{17}$ AmERICAN Geriatric SOCIETY (1987) AIDS, aides and aging. Clinical Report on Aging, 1, 2.

\section{North East Thames Regional Health Authority \\ Consultant Appointments in Psychiatry for 1987}

Dr G. S. Ibrahimi, Consultant in Psychogeriatrics in Haringey \& Hampstead, 22 January 1987.

Dr J. Katwala, Consultant in Child Psychiatry in Southend, Essex, 17 February 1987.

Dr M. K. Seneviratana, Consultant in Mental Handicap in Mid Essex, 1 April 1987.

Dr E. C. Johnson-Sabine, Consultant in Mental Illness in Haringey, 9 June 1987.
Dr J. W. Coid, Consultant in Forensic Psychiatry in Haringey, 1 September 1987.

Dr S. Isaacs, Consultant in Child Psychiatry in Waltham Forest, Essex, 1 September 1987.

Dr J. P. Meehan, Consultant in Mental Illness in Waltham Forest, Essex, 2 November 1987.

The Editors would welcome information about recent consultant appointments from other Regional Health Authorities.

\section{New Publication}

Behaviour Problems in Mental Handicap: An Annotated Bibliography 1970-1985. By Kenneth Day, Joyce Hamilton and Paul Smith. London: Gaskell (Royal College of Psychiatrists). 1988. Pp 144. £7.50.

The purpose of this bibliography is to present the literature in an orderly fashion, and in an annotated form, which will be of use to practitioners, service planners, those running professional training courses, and researchers.

It is concerned only with behaviour problems: mental illness superimposed on mental handicap, and delinquency, are not covered. There is a brief list of recent reviews of autism: articles on that subject are included where there are associated mental handicap and behaviour problems. 